ఠ

\title{
Prognostic biomarkers for patients with advanced renal cell carcinoma treated with VEGF-targeted tyrosine kinase inhibitors
}

This article was published in the following Dove Press journal:

OncoTargets and Therapy

12 June 2013

Number of times this article has been viewed

\section{Daniel C Cho}

Division of Hematology and Oncology, Beth Israel Deaconess Medical Center, Boston, MA, USA
Correspondence: Daniel C Cho Beth Israel Deaconess Medical Center, 330 Brookline Avenue, MASCO 4I4, Boston, MA 02215, USA

$\mathrm{Tel}+\mathrm{I} 6176329250$

Fax + I 6176329260

Email dchol@bidmc.harvard.edu
Abstract: Tyrosine kinase inhibitors with activity against vascular endothelial growth factor receptor 2 are now standard treatment for the majority of patients with advanced renal cell carcinoma. The clinical development of these agents followed by their broad clinical utilization has allowed the creation of large databases to facilitate the identification of prognostic biomarkers and development of prognostic models. While several clinical prognostic models have been created, work continues on identifying novel biomarkers which might be used in conjunction with or even in place of these clinical models. In this review, we discuss the progress thus far in improving on current prognostic models and speculate on possible developments in the near future.

Keywords: renal cancer, prognostic biomarker, VEGF tyrosine kinase inhibitors

\section{Introduction}

Within recent years, receptor tyrosine kinase inhibitors (TKI) directed against vascular endothelial growth factor (VEGF) signaling have been established as standard of care for the majority of patients with advanced renal cell carcinoma of clear cell histology. Currently, four TKI with activity against VEGF receptor 2 (VEGFR2) are approved by the United States Food and Drug Administration and widely administered to patients with advanced renal cell carcinoma. This broad clinical experience has allowed the creation of large databases which have facilitated the exploration of prognostic factors specific to patients treated with these agents. In this review, we discuss the current status of these prognostic biomarkers and their potential utility in both patient care and clinical investigation.

\section{Prognostic versus predictive biomarkers}

A biomarker is a measurable characteristic which can be an indicator of a biologic process, both normal and pathologic. In oncology, biomarkers are most frequently used to indicate clinical events, such as disease onset, recurrence, response to therapy, or survival. A prognostic biomarker relates to the natural history of the underlying cancer independent of therapy, whereas predictive biomarkers reflect the likelihood of differential responses to certain interventions. With respect to patients specifically treated with VEGF-targeted TKI, the distinction becomes murkier. In principle, prognostic factors are those which reflect the likelihood of clinical outcomes such as disease control (progression-free survival) or overall survival regardless of whether the patient is actually treated with a VEGF-targeted agent or not. In contrast, a truly predictive biomarker reflects the likelihood of similar clinical outcomes in patients who 
are actually treated and may not have relevance in patients who are not treated. Because the establishment of a biomarker as predictive typically requires concurrent validation in a control group, the vast majority of biomarkers studied in renal cell carcinoma thus far must be considered prognostic and we focus on these in this review.

\section{Clinical and laboratory-based prognostic factors}

A multitude of clinical and laboratory-based factors have been identified as having prognostic value in patients with renal cell carcinoma. These factors have included the presence of constitutional symptoms, poor performance status, markers of inflammation such as erythrocyte sedimentation rate or C-reactive protein, measures of tumor burden, elevated lactate dehydrogenase, hypercalcemia, anemia, and thrombocytosis. Many of these factors have been incorporated into prognostic models through multivariate analysis. For patients with all stages of renal cell carcinoma, perhaps the best known of these models are the University of California Los Angeles integrated staging system and the Mayo Clinic metastasesfree survival scoring system. ${ }^{1,2}$ The University of California Los Angeles integrated staging system integrated several tumor-based factors, such as tumor-node-metastasis stage, Furhman's grade, and Eastern Cooperative Oncology Group performance status, into a prognostic model for survival in patients undergoing nephrectomy. The Mayo Clinic metastases-free survival scoring system integrates tumor stage, regional lymph node status, tumor size, Fuhrman's nuclear grade, and presence of tumor necrosis into a prognostic model for the risk of developing metastases in patients undergoing nephrectomy.
While these two models are useful for prognosis in patients undergoing nephrectomy, the best known prognostic model for patients with metastatic disease is that developed at the Memorial Sloan Kettering Cancer Center. This model groups patients into favorable, intermediate-risk, and high-risk groups based on the presence of risk factors including low Karnofsky performance status, high lactate dehydrogenase, elevated serum calcium, low hemoglobin, and absence of prior nephrectomy. ${ }^{3}$ This model was later modified to be specific to treatment with interferon- $\alpha$ and included the same risk factors with the exception of the absence of prior nephrectomy, which was replaced with a time from diagnosis to treatment of less than one year. ${ }^{4}$

Although the Memorial Sloan Kettering Cancer Center model also appears to be valid in the TKI era, ${ }^{5}$ many other prognostic models have been developed or are specific for patients treated with VEGF-targeted agents. Although these models are described in Table 1, one model deserves special note because it has recently been externally validated. Heng et al originally reported the findings of the International Metastatic Renal Cell Database Consortium in 2009 in a study of 645 patients with treatment-naive metastatic renal cell carcinoma who underwent therapy with a VEGFtargeted agent. ${ }^{6}$ The investigators identified six independent prognostic factors for overall survival in this group of patients: anemia (hemoglobin less than the lower limit of normal); hypercalcemia (corrected calcium greater than the upper limit of normal); Karnofsky performance status less than $80 \%$; time from diagnosis to treatment of less than one year; neutrophilia (neutrophil count greater than the upper limit of normal); and thrombocytosis (platelet count greater than the upper limit of normal). Patients were then

Table I Three models used for prognostic prediction based on risk factors in patients with renal cell carcinoma

\begin{tabular}{|c|c|c|}
\hline Prognostic model & Risk factors & Prognostic prediction \\
\hline Cleveland Clinic Foundation ${ }^{9}$ & $\begin{array}{l}\text { Interval from diagnosis to treatment }<2 \text { years } \\
\text { Baseline corrected serum calcium }<8.5 \mathrm{mg} / \mathrm{dL} \text { or }>10 \mathrm{mg} / \mathrm{dL} \\
\text { ECOG performance status }>0 \\
\text { Neutrophil count }>4.5 \times 10^{9} / \mathrm{L} \\
\text { Platelet count }>300 \times 10^{9} / \mathrm{L}\end{array}$ & $\begin{array}{l}0 \text { - I risk factors, median PFS } 20.1 \text { months } \\
2 \text { risk factors, median PFS I } 3 \text { months } \\
\geq 3 \text { risk factors, median PFS } 3.9 \text { months }\end{array}$ \\
\hline $\begin{array}{l}\text { International Kidney Cancer } \\
\text { Working Group }{ }^{10}\end{array}$ & $\begin{array}{l}\text { Prior treatment, performance status, number of metastatic } \\
\text { sites, time from diagnosis to treatment, hemoglobin, white } \\
\text { blood count, lactate dehydrogenase, alkaline phosphatase, } \\
\text { and serum calcium }\end{array}$ & $\begin{array}{l}\text { Favorable: median survival } 26.9 \text { months } \\
\text { Intermediate: median survival } \\
\text { I I.5 months } \\
\text { Poor: median survival } 4.9 \text { months }\end{array}$ \\
\hline International Renal Cell & Karnofsky performance status $<80 \%$ & 0 risk factors: median OS 43.2 months \\
\hline Carcinoma Database & Less than one year from diagnosis to treatment & I-2 risk factors: median OS 22.5 months \\
\hline Consortium ${ }^{6,7}$ & $\begin{array}{l}\text { Anemia } \\
\text { Hypercalcemia } \\
\text { Neutrophilia } \\
\text { Thrombocytosis }\end{array}$ & $\geq 3$ risk factors: median OS 7.8 months \\
\hline
\end{tabular}

Abbreviations: ECOG, Eastern Cooperative Oncology Group; OS, overall survival; PFS, progression-free survival. 
identified as having a favorable (no risk factors), intermediate (1-2 risk factors), or poor ( $\geq$ three risk factors) prognosis. In the independent validation of this model in 1028 patients treated with first-line VEGF-targeted agents, the median overall survival associated with these prognostic groups was 43.2 months, 22.5 months, and 7.8 months, respectively. ${ }^{7}$ The prognostic model of the International Metastatic Renal Cell Database Consortium is currently the only externally validated model specific for patient undergoing first-line therapy with VEGF-targeted agents and therefore will likely become the standard model for risk stratification in both clinical decision-making and clinical trials.

In contrast with the first-line setting, prognostic factors for patients receiving VEGF-targeted TKI as second-line therapy are less established. As a continuation of their initial report of the International Renal Cell Database Consortium, Vickers et al reported that a higher baseline Karnofsky performance score prior to first-line therapy predicted a greater likelihood of receiving a second-line therapy. ${ }^{8}$ While many groups have suggested that progression-free survival with first-line VEGF-targeted TKI is not predictive of response to a second VEGF-targeted TKI, it may be prognostic with respect to progression-free survival on second-line therapy. ${ }^{9-12}$ Ultimately, however, it is not clear that second-line and further therapy alters the prognosis established in the first-line setting.

\section{Clinical pharmacodynamic markers}

While most prognostic models have utilized baseline clinical factors, it is becoming increasingly clear that similar prognostic information may be gained from pharmacodynamic changes in response to treatment. As a therapeutic class, antagonists of VEGF signaling produce a number of characteristic mechanism-based toxicities. The correlation of the occurrence of these toxicities with clinical outcomes has been rigorously studied throughout the clinical development of the VEGF-targeted TKI. The most solidly established toxicity with respect to prognosis appears to be the development of hypertension. In a small retrospective analysis of adverse events experienced in 32 patients as a result of sunitinib treatment versus response, Rixe et al reported that only the occurrence or worsening of hypertension was associated with improved clinical response. ${ }^{13}$ In larger pooled analysis of 544 patients treated with sunitinib, Rini et al reported that patients who developed treatment-related systolic hypertension has superior outcomes compared with those who did not with respect to objective response rate (54.8\% versus $8.7 \%$ ), median progression-free survival (12.5 versus 2.5 months), and overall survival (30.9 versus 7.2 months). ${ }^{14}$ This concept was also validated retrospectively for axitinib through a secondary analysis of the Phase III trial of axitinib versus sorafenib in patients with previously treated renal cell carcinoma. ${ }^{15}$ The value of dose titration until hypertension is currently being assessed prospectively in a randomized double-blind Phase II trial of axitinib in patients with advanced renal cell carcinoma (NCT00835978). While there is little doubt that treatmentrelated hypertension is a prognostic factor for patients treated with VEGF-targeted TKI, the wide adoption of the practice of dose titration until hypertension is observed with these agents will likely significantly diminish its value as a distinguishing marker.

\section{Blood-based biomarkers}

Throughout the clinical development of VEGF-targeted TKI, blood has provided a convenient source of potential biomarkers. The ease of collection of specimens and measurement has led to the observation that a multitude of circulating factors are modulated by treatment with VEGFtargeted agents. Many of these circulating factors have been studied in the context of large clinical studies and have shown promise as prognostic biomarkers.

Not surprisingly, much of the early work on circulating biomarkers focused on the various VEGF and VEGF receptor isoforms. Rini et al first reported that baseline circulating levels of soluble VEGF receptor 3 (VEGFR3) and VEGF-C levels may be prognostic of progression-free survival in response to treatment with sunitinib. ${ }^{16}$ Higher circulating levels of VEGF-A were also shown to be associated with lower overall survival in both the treatment and placebo groups of the Phase III TARGET trial of sorafenib versus placebo. ${ }^{17}$ A higher baseline VEGF-A level was also correlated with shorter progression-free survival in either arm of the Phase III AVOREN trial comparing bevacizumab plus interferon with interferon alone. ${ }^{18}$ Finally, baseline circulating VEGF-A levels were recently shown to be prognostic of overall survival but not predictive of benefit from treatment in four separate Phase III trials of bevacizumab in renal cell, colorectal, and lung carcinoma. ${ }^{19}$

In addition to VEGF, many other soluble prognostic biomarkers have been identified. For example, a subsequent analysis of the TARGET study showed that plasma levels of tissue inhibitor of metalloproteinase-1 was an independent prognostic biomarker for overall survival. ${ }^{20}$ Another recent study has suggested that a higher serum C-reactive peptide level is an independent prognostic factor for shorter 
progression-free survival and overall survival in patients treated with sunitinib. ${ }^{21}$ One of the most widely corroborated circulating biomarkers is serum interleukin-6. Several studies have shown that serum interleukin-6 is an independent prognostic marker for progression-free and overall survival in patients with metastatic renal cell carcinoma. ${ }^{18,22,23}$ An analysis of plasma cytokines and angiogenic factors in blood collected from patients as part of Phase III trials of pazopanib confirmed that higher baseline interleukin-6 levels, along with those of interleukin- 8 and osteopontin, were prognostic for a shorter progression-free survival. ${ }^{24}$ Interestingly, within the study population, these same factors were prognostically stronger than Eastern Cooperative Oncology Group performance status and prognostic systems based on clinical factors, such as those from the Memorial Sloan Kettering Cancer Center and the International Renal Cell Database Consortium. Higher baseline interleukin-6 levels were also found to be predictive of a progression-free survival benefit from treatment with pazopanib compared with placebo. Interleukin-6 is now being proposed for prospective assessment as a predictive biomarker in clinical trials.

Efforts are ongoing to identify other markers in the blood besides circulating cytokines and angiogenic factors. Many groups have focused on potentially novel biomarkers such as circulating endothelial cells or circulating tumor cells. While these remain biologically enticing given the mechanism of action of VEGF-targeted TKI, the paucity of these types of cells in the circulation has made their detection and assessment extremely difficult thus far and a major technical limitation. In the meantime, however, consideration must be given to incorporating the more widely studied blood-based markers, particularly VEGF-A and interleukin-6, into the more established clinical models to strengthen their potential prognostic value.

\section{Tissue-based models}

Like the blood-based biomarkers, many of the most rigorously explored tissue-based prognostic biomarkers for patients treated with VEGF-targeted TKI are related to the mechanism of action of this class of agent. The majority of clear cell renal cell carcinoma are characterized by bi-allelic dysfunction of the von Hippel-Lindau ( $V H L)$ gene, resulting in inappropriate accumulation of hypoxia-inducible factor (HIF)- $1 \alpha$ and HIF-2 $\alpha$, with subsequent activation of their downstream genes, including those for VEGF and platelet-derived growth factor (PDGF). Because the TKIs approved for the treatment of renal cell carcinoma all share activity against VEGFR2 and PDGF receptor (PDGFR)- $\beta$, it is not surprising that many investigators have studied the correlation between VHL loss and outcomes in patients treated with these agents. In the largest such analysis including tumor specimens and outcomes from 123 patients treated with VEGF-targeted therapy, Choueiri et al reported that patients whose tumor specimens showed a loss of function mutation in $V H L$ had a response rate of $52 \%$ versus $31 \%$ in wild-type patients, and that loss of function mutation was an independent prognostic factor for improved response on multivariate analysis. ${ }^{25}$ However, these findings must be validated in a larger patient population before their incorporation into existing prognostic models.

Many investigators have expanded upon genetic analysis to include studies of polymorphisms and chromosome copy numbers. For example, Bianconi et al recently reported that certain single nucleotide polymorphisms in VEGF or VEGFR may predict benefit from treatment with either sunitinib or pazopanib. ${ }^{26}$ Similarly, Jonasch et al have reported their finding that chromosomal copy number variation may provide prognostic information in patients treated with VEGF-targeted agents. ${ }^{27}$ Specifically, gain of $8 \mathrm{q}$ and loss of $16 \mathrm{q}, 20 \mathrm{p}$, or $20 \mathrm{q}$ were associated with a shorter overall survival, while gain of $1 \mathrm{q}$ and $5 \mathrm{q}$ was associated with longer overall survival. Currently, these studies remain preliminary and must be validated prospectively in larger patient samples.

In addition to genetic analysis, many biomarkers have been investigated based on expression as determined by immunohistochemistry. Patel et al reported that high expression of both HIF- $1 \alpha$ and HIF- $2 \alpha$ in renal cell carcinoma specimens was correlated with a higher likelihood of objective response to sunitinib. ${ }^{28}$ Despite these findings, these results have not been able to be reproduced across larger patient populations and across different VEGF-targeted agents. It is possible that broad application of this marker is limited by technical considerations, such as the lack of an antibody against HIF- $1 \alpha$ and HIF- $2 \alpha$ which can reliably and reproducibly detect expression across different tissue specimens. Despite these technical limitations, variable expression of the HIFs remains a potentially interesting biomarker worthy of further investigation.

In addition to expression of HIF itself, other investigators have focused on expression of gene products regulated by HIF. One such gene regulated by HIF-1 $\alpha$ which has been investigated extensively in renal cell carcinoma is carbonic anhydrase IX, a surface transmembrane enzyme believed to be responsible for maintaining an acidic extracellular $\mathrm{pH}$. 
Carbonic anhydrase IX expression can be detected in up to $90 \%$ of renal cell carcinoma specimens, and its expression has been shown to be inversely correlated with both overall survival and likelihood of developing metastases. ${ }^{29}$ Therefore, carbonic anhydrase IX expression may have value as both a diagnostic and prognostic marker in early-stage renal cell carcinoma. Unfortunately, studies thus far have failed to establish the prognostic or predictive value of carbonic anhydrase IX expression with respect to VEGF-targeted TKI. ${ }^{30,31}$ Overall, while immunohistochemical analysis has identified several interesting biomarkers, this approach remains limited by technical considerations, such as reliance on availability of reliable antibodies, stability of epitopes, and an inherent subjectivity in interpretation.

\section{Novel biomarkers}

Although a multitude of biomarkers are under exploration in renal cell carcinoma using various technology platforms, several recently identified genetic alterations in renal cell carcinoma are worthy of special attention in the coming years with respect to prognosis in patients treated with VEGFtargeted TKI. Results of both targeted and unsupervised sequencing studies in renal cell carcinoma have recently shown that several genes which function in histone modification and chromatin remodeling are frequently mutated in clear cell renal cell carcinoma, including PBRM1, BAP1, SETD2, KDM5C, and $A R I D 1 A .^{32-36}$ The most commonly mutated of these is $P R B M 1$, which encodes the BAF180 protein, a member of the PBAF SWI/SNF chromatin remodeling complex. Truncating mutations in PBRM1 have been described in up to $41 \%$ of clear cell renal cell carcinomas. ${ }^{32}$ BAP1, which encodes a nuclear deubiquitinase, has also recently been shown to be inactivated by bi-allelic alteration in up to $15 \%$ of clear cell renal cell carcinomas. ${ }^{33}$ Likewise, SETD2, which encodes a histone methyltransferase, is mutated in approximately $8 \%$ of clear cell renal cell carcinomas. ${ }^{34}$ Not surprisingly, correlation of the presence of these mutations with clinical outcomes is already providing prognostic information. In a recently published analysis, Hakimi et $\mathrm{al}^{36}$ were able to show that patients whose tumors possessed mutations in PBRM1, BAP1, SETD2, or KDM5C were more likely to present with advanced stage and grade. Similarly, Kapur $^{37}$ et al showed that patients whose renal cell carcinoma possessed mutations in BAP1 had a significantly shorter overall survival than those whose renal cell carcinoma possessed mutations in PBRM1. These authors also identified a smaller subset of patients, ie, those whose renal cell carcinoma contained mutations of both BAP1 and PBRM1, who had a particularly shorter overall survival.
Although work correlating the presence of these mutations with clinical outcomes in patients treated with VEGF-targeted TKI has not yet been published, such analysis is ongoing. It is hoped that the mutational data on these chromatin remodeling and histone modifying genes, in conjunction with loss of VHL, might provide valuable prognostic and predictive information which can be incorporated into the established clinical models to not only stratify patients in clinical trials but also potentially guide therapeutic decisions.

\section{Conclusion}

Tremendous progress has been made in creating and optimizing clinical prognostic models. Efforts are ongoing to identify novel biomarkers which might be used in conjunction with or possibly even in place of the current clinical models. While several promising markers such as serum VEGF-A and interleukin- 6 have emerged, these markers must be validated prospectively and independently before they can be adopted into clinical use. At the same time, identification of novel genes which are frequently mutated in renal cell carcinoma suggests that a new, largely genetic classification scheme for renal cell carcinoma may be emerging. Although this must be considered conjecture at this point, a new classification scheme might have major prognostic implications with respect to not only VEGF-targeted therapies but other treatment modalities across renal cell carcinoma as well.

\section{Disclosure}

The author reports no conflicts of interest in this work.

\section{References}

1. Zisman A, Pantuck AJ, Dorsey F, et al. Improved prognostication of renal cell carcinoma using an integrated staging system. J Clin Oncol. 2001;19:1649-1657.

2. Frank I, Blute ML, Cheville JC, Lohse CM, Weaver AL, Zincke H. An outcome prediction model for patients with clear cell renal cell carcinoma treated with radical nephrectomy based on tumor stage, size, grade and necrosis: the SSIGN score. J Urol. 2002;168:2395-2400.

3. Motzer RJ, Mazumdar M, Bacik J, et al. Survival and prognostic stratification of 670 patients with advanced renal cell carcinoma. J Clin Oncol. 1999;17:2530-2540.

4. Motzer RJ, Bacik J, Murphy BA, Russo P, Mazumdar M. Interferon-alfa as a comparative treatment for clinical trials of new therapies against advanced renal cell carcinoma. J Clin Oncol. 2002;20:289-296.

5. Hoffmeister I, Riesenback L, Bjerer S, et al. Validation of MSKCCcriteria in metastatic renal cancer patients treated with sorafenib or sunitinib. J Clin Oncol. 2011;29 Suppl 7:Abstr 401.

6. Heng DY, Xie W, Regan MM, et al. Prognostic factors for overall survival in patients with metastatic renal cell carcinoma treated with vascular endothelial growth factor-targeted agents: results from a large, multi-center study. J Clin Oncol. 2009;27:5794-5799.

7. Heng DY, Xie W, Regan MM, et al. External validation and comparison with other models of the International Metastatic Renal-Cell Carcinoma Database Consortium prognostic model: a population-based study. Lancet Oncol. 2013;14:141-148. 
8. Vickers MM, Choueiri TK, Rogers M, et al. Clinical outcome in metastatic renal cell carcinoma patients after failure of initial vascular endothelial growth factor-targeted therapy. Urology. 2010;76:430-434.

9. Choueiri TK, Garcia JA, Elson P, et al. Clinical factors associated with outcome in patients with metastatic clear-cell renal cell carcinoma treated with vascular endothelial growth factor-targeted therapy. Cancer. 2007;110:543-550.

10. Manola J, Royston P, Elson P, et al. Prognostic model for survival in patients with metastatic renal cell carcinoma: results from the International Kidney Cancer Working Group. Clin Cancer Res. 2011;17: $5443-5450$

11. Al-Marrawi MY, Rini BI, Harshman LC, et al. The association of clinical outcome to first-line VEGF-targeted therapy with clinical outcome to second-line VEGF-targeted therapy in metastatic renal cell carcinoma patients. Target Oncol. January 9, 2013. [Epub ahead of print.]

12. Seidel C, Busch J, Weikert S, et al. Progression free survival of first line vascular endothelial growth factor-targeted therapy is an important prognostic parameter in patients with metastatic renal cell carcinoma. Eur J Cancer. 2012;48:1023-1030.

13. Rixe O, Billemont B, Izzedine H. Hypertension as a predictive factor of sunitinib activity. Ann Oncol. 2007;18:1117.

14. Rini BI, Cohen DP, Lu DR. Hypertension as a biomarker of efficacy in patients with metastatic renal cell carcinoma treated with sunitinib. J Natl Cancer Inst. 2011;103:763-773.

15. Rini BI, Escudier B, Tomczak P, et al. Comparative effectiveness of axitinib versus sorafenib in advanced renal cell carcinoma (AXIS): a randomised phase 3 trial. Lancet. 2011;378:1931-1939.

16. Rini BI, Michaelson MD, Rosenberg JE, et al. Antitumor activity and biomarker analysis of sunitinib in patients with bevacizumab-refractory advanced renal cell carcinoma. J Clin Oncol. 2008;26:3743-3748.

17. Escudier B, Eisen T, Stadler WM, et al. Sorafenib for treatment for renal cell carcinoma: final efficacy and safety results of the phase III treatment approaches in renal cancer global evaluation trial. $J$ Clin Oncol. 2009;27:3312-3318.

18. Escudier B, Ravaud A, Negrier S, et al. Update on the AVOREN trial in metastatic renal cell carcinoma (mRCC): efficacy and safety in subgroups of patients (pts) and pharmacokinetic (PK) analysis. J Clin Oncol. 2008;26 Suppl:Abstr 5025.

19. Hegde PS, Jubb AM, Chen D, et al. Predictive impact of circulating vascular endothelial growth factor in four Phase III trials evaluating bevacizumab. Clin Cancer Res. 2013;19:929-937.

20. Pena C, Lathia L, Shan M, Escudier B, Bukowski RM. Biomarkers predicting outcome in patients with advanced renal cell carcinoma: Results from sorafenib phase III treatment approaches in renal cancer global evaluation trial. Clin Cancer Res. 2010;16:4853-4863.

21. Yann-Alexandre V, Beuselinck B, Wolter P, et al. Prognostic impact of baseline serum C-reactive protein in metastatic renal cell carcinoma treated with sunitinib. J Clin Oncol. 2013;31 Suppl:Abstr 425.

22. Negrier S, Perol D, Menetrier-Caux C, et al. Interleukin-6, interleukin-10, and vascular endothelial growth factor in metastatic renal cell carcinoma: prognostic value of interleukin-6- from the Groupe Francais d'Immunotherapie. J Clin Oncol. 2004;22:2371-2378.

23. Montero AJ, Diaz-Montero CM, Millikan RE, et al. Cytokines and angiogenic factors in patients with metastatic renal cell carcinoma treated with interferon-alpha: association of pretreatment serum levels with survival. Ann Oncol. 2009;20:1682-1687.

OncoTargets and Therapy

\section{Publish your work in this journal}

OncoTargets and Therapy is an international, peer-reviewed, open access journal focusing on the pathological basis of all cancers, potential targets for therapy and treatment protocols employed to improve the management of cancer patients. The journal also focuses on the impact of management programs and new therapeutic agents and protocols on
24. Tran HT, Liu Y, Zurita AJ, et al. Prognostic or predictive plasma cytokine and angiogenic factors for patients treated with pazopanib for metastatic renal-cell cancer: a retrospective analysis of phase 2 and phase 3 trials. Lancet Oncol. 2012;13:827-837.

25. Choueiri TK, Vaziri SA, Jaeger E, et al. von Hippel-Lindau gene status and response to vascular endothelial growth factor targeted therapy for metastatic clear cell renal cell carcinoma. J Urol. 2008;180:860-865.

26. Bianconi M, Scartozzi M, Faloppi L, et al. Effect of VEGF and VEGFR polymorphisms on clinical outcome and response in patients with advanced renal cell carcinoma receiving first-line treatment. J Clin Oncol. 2013;31 Suppl:Abstr 388.

27. Jonasch E, Thakur S, Sircar K, et al. Impact of chromosomal copy number variation on outcome in metastatic clear cell renal cell carcinoma patients treated with antiangiogenic agents. J Clin Oncol. 2013; 31 Suppl:Abstr 393

28. Patel P, Chadalavada R, Ishill N, et al. Hypoxia-inducible factor (HIF) $1 \alpha$ and $2 \alpha$ levels in cell lines and human tumor predicts response to sunitinib in renal cell carcinoma (RCC). $J$ Clin Oncol. 2008;26 Suppl:Abstr 5008.

29. Bui MH, Seligson D, Han KR, et al. Carbonic anhydrase IX is an independent predictor of survival in advanced renal clear cell carcinoma: implications for prognosis and therapy. Clin Cancer Res. 2003;9: 802-811.

30. Choueiri TK, Regan MM, Rosenberg JE, et al. Carbonic anhydrase IX and pathological features as predictors of outcome in patients with metastatic clear-cell renal cell carcinoma receiving vascular endothelial growth factor-targeted therapy. BJU Int. 2010;106:772-778.

31. Choueiri TK, Cheng S, Qu AQ, Pastorek J, Atkins MB, Signoretti S. Carbonic anhydrase IX as a potential biomarker of efficacy in metastatic clear-cell renal cell carcinoma patients receiving sorafenib or placebo: analysis from the treatment approaches in renal cancer global evaluation trial (TARGET). Urol Oncol. 2012; doi:pii: S1078-1439(12)00246-3.

32. Varela I, Tarpey P, Raine K, et al. Exome sequencing identifies frequent mutation of the SWI/SNF complex gene PBRM1 in renal carcinoma. Nature. 2011;469:539-542.

33. Peña-Llopis S, Vega-Rubín-de-Celis S, Liao A, et al. BAP1 loss defines a new class of renal cell carcinoma. Nat Genet. 2012;44:751-759.

34. Dalgliesh GL, Furge K, Greenman C, et al. Systematic sequencing of renal carcinoma reveals inactivation of histone modifying genes. Nature. 2010;463:360-363.

35. Lichner Z, Scorilas A, White NM, et al. The chromatin remodeling gene ARID1A is a new prognostic marker in clear cell renal cell carcinoma. Am J Pathol. 2013;182:1163-1170.

36. Hakimi AA, Chen YB, Wren J, et al. Clinical and pathologic impact of select chromatin-modulating tumor suppressors in clear cell renal cell carcinoma. Eur Urol. 2013;63:848-854.

37. Kapur P, Peña-Llopis S, Christie A, et al. Effects on survival of BAP1 and PBRM1 mutations in sporadic clear-cell renal-cell carcinoma: a retrospective analysis with independent validation. Lancet Oncol. 2013;14:159-167.

patient perspectives such as quality of life, adherence and satisfaction The manuscript management system is completely online and includes a very quick and fair peer-review system, which is all easy to use. Visit http://www.dovepress.com/testimonials.php to read real quotes from published authors. 